\title{
Electronic Properties of In Situ Prepared Nanocrystalline Fe-Ni-Ti Alloy Thin Films
}

\author{
S. PACANOWski ${ }^{a, *}$, J. Skoryna ${ }^{b}$, A. MArCZYŃskA ${ }^{b}$, D. Skoryna ${ }^{b}$ And L. Smardz ${ }^{b}$ \\ ${ }^{a}$ Faculty of Technical Physics, Poznań University of Technology, Piotrowo 3, 60-965 Poznań, Poland \\ ${ }^{b}$ Institute of Molecular Physics, Polish Academy of Sciences, M. Smoluchowskiego 17, 60-179 Poznań, Poland

\begin{abstract}
In this contribution we study experimentally the electronic properties of nanocrystalline $\mathrm{Fe}-\mathrm{Ni}-\mathrm{Ti}$ alloy thin
\end{abstract} \\ films using X-ray photoelectron spectroscopy. The structure of the samples has been studied by X-ray diffraction. \\ Their bulk chemical compositions were measured using X-ray fluorescence method. The surface chemical compo- \\ sition and the cleanness of all samples were checked in situ, immediately after deposition, transferring the samples \\ to an UHV analysis chamber equipped with X-ray photoelectron spectroscopy. X-ray diffraction studies revealed \\ the formation of nanocrystalline $\mathrm{Fe}-\mathrm{Ni}-\mathrm{Ti}$ alloy thin films at a substrate temperature of about $293 \mathrm{~K}$. In situ \\ X-ray photoelectron spectroscopy studies showed that the valence bands of nanocrystalline samples are broader \\ compared to those measured for the polycrystalline bulk alloys. Such modifications of the valence bands of the \\ nanocrystalline alloy thin films could influence on their hydrogenation properties.
}

DOI: 10.12693/APhysPolA.127.436

PACS: 73.22.-f, 68.55.-a

\section{Introduction}

The studies of metal hosts for hydrogen has attracted scientific attention for many decades $[1,2]$ and is interesting from both basic research and technological points of view. The small size of hydrogen atoms permits dense hydrogen packing in metal that has a high affinity to hydrogen, i.e., a large negative heat of solution for hydrogen. In metal hydrides, hydrogen density can be even greater than in liquid hydrogen [3,4]. This has led to the application of metal hydrides for energy storage [5]. However, for transport applications, the volume as well as weight of the host are of major concern [5,6], which has resulted in the exclusion of many metals from use in applications. Reversible charging and discharging at moderate temperatures together with high volumetric and gravimetric densities is required for the utilization of hydrogen as an energy carrier. Several semi-empirical models [7, 8] have been proposed for the heat of formation and heat of solution of metal hydrides and attempts have been made for justifying the maximum hydrogen absorption capacity of the metallic matrices. These models showed that the energy of the metal-hydrogen interaction depends both on geometric and electronic factors. In order to optimise the choice of the metal hosts for a selected application, a better understanding of the role of each alloy constituent on the electronic properties of the material is crucial. Furthermore, in the search of optimized materials for applications, microstructural aspects are also very important [9-11].

Materials properties are strongly affected by microstructural contributions, therefore the microstructure

* corresponding author; e-mail: sebastian@ifmpan.poznan.pl can be used to tune materials properties for applications. For example, the properties of Mg-based alloys are improved by ball milling, which was attributed to the finegrain structure of the metal alloy $[10,12]$. Ball milling leads to shorter process times and enhances the hydrogen kinetics [9, 12]. Small additions of metal or oxide particles also positively change the uptake kinetics [13, 14].

It is well known that the film's grain size can increase starting from the substrate interface, resulting with many grain boundaries in such samples [15]. Dislocations and vacancies are present in higher density than in bulk material. Even when the grain size is maximized by epitaxial film growth, dislocations are generated during the film's growth process to adjust for the lattice mismatch between the film and substrate [16]. The local hydrogen affinity is different for these defects and therefore the materials properties are expected to be influenced by all these microstructural components.

In this contribution we study experimentally the electronic properties of nanocrystalline $\mathrm{Fe}-\mathrm{Ni}-\mathrm{Ti}$ alloy thin films using X-ray photoelectron spectroscopy (XPS). According to the semi-empirical hydrogenation models $[7,8]$, these measurements may supply useful indirect information about the influence of the electronic structure of nanocrystalline alloys on their hydrogenation properties.

\section{Experimental procedure}

$\mathrm{Fe}-\mathrm{Ni}-\mathrm{Ti}$ alloy thin films were prepared onto oxidised $\mathrm{Si}(100)$ substrates in the temperature range of $285-700 \mathrm{~K}$ using computer-controlled ultra high vacuum (UHV) magnetron co-sputtering. The total thickness of the samples was about $1000 \mathrm{~nm}$. The base pressure before the deposition process was lower than $5 \times 10^{-10}$ mbar. Typical sputtering conditions are listed in Table. As a sub- 
strate we have used $\mathrm{Si}(100)$ wafers with an oxidised surface to prevent a silicide formation. Therefore we have applied a special heat treatment in UHV before deposition in order to obtain an epitaxial $\mathrm{SiO}_{2}$ surface layer [17]. The distance between target and substrate was about $220 \mathrm{~mm}$. The chemical composition and the cleanness of all layers was checked in situ, immediately after deposition, transferring the samples to an UHV analysis chamber equipped with XPS [18]. The electronic properties of the prepared samples were studied in situ using XPS. The structure of the samples has been studied by Xray diffraction (XRD). Their bulk chemical compositions were measured using X-ray fluorescence (XRF) method.

TABLE

Typical sputtering condition used for deposition of $\mathrm{Fe}^{-}$ $\mathrm{Ni}-\mathrm{Ti}$ alloy thin films.

\begin{tabular}{l|c|c|c}
\hline \hline Parameter & Unit & Ti & Ni (Fe) \\
\hline $\begin{array}{l}\text { rest gas } \\
\text { pressure }\end{array}$ & mbar & \multicolumn{2}{|c}{$5 \times 10^{-10}$} \\
\hline $\begin{array}{l}\text { Ar partial } \\
\text { pressure }\end{array}$ & mbar & \multicolumn{2}{|c}{$5 \times 10^{-4}$} \\
\hline $\begin{array}{l}\text { Ar purity } \\
\text { target }\end{array}$ & $\%$ & 99.9998 \\
diameter & mm & 99.99 & $99.99(99.97+)$ \\
\hline $\begin{array}{l}\text { target } \\
\text { purity }\end{array}$ & $\%$ & magnetron RF & magnetron DC \\
\hline $\begin{array}{l}\text { sputtering } \\
\text { method }\end{array}$ & - & $40-75$ & $20-60$ \\
\hline $\begin{array}{l}\text { sputtering } \\
\text { power }\end{array}$ & $\mathrm{W}$ & $0.01-0.04$ & $0.03-0.1$ \\
\hline $\begin{array}{l}\text { deposition } \\
\text { rate }\end{array}$ & $\mathrm{nm} / \mathrm{s}$ & & \multicolumn{2}{|c}{5} \\
\end{tabular}

\section{Results and discussion}

Results on XRF measurements revealed the assumed bulk chemical composition of the prepared alloy thin films. Structural studies showed that the samples deposited at temperature of about $293 \mathrm{~K}$ are nanocrystalline with average grain size $D \approx 20-25 \mathrm{~nm}$.

In Fig. 1 we show XPS core-level spectra of the freshly prepared nanocrystalline $\mathrm{NiFe}$ and $\mathrm{FeTi}$ thin films. The total thickness of the prepared thin film samples was about $1000 \mathrm{~nm}$. Due to well known high reactivity of titanium with oxygen we have prepared the nanocrystalline alloy thin films after an additional heating of the sample holder and substrate at $700 \mathrm{~K}$ for $3 \mathrm{~h}$ and cooling to $293 \mathrm{~K}$ under UHV conditions. Results showed that after such an outgassing procedure, it is possible to prepare oxygen- and carbon-free surface. The oxygen and other impurities are practically absent on the surface of such prepared thin films. Practically no XPS signal from potential contamination atoms like O $1 s$ and $\mathrm{C} 1 s$ is observed (Fig. 1). On the other hand, we have observed oxygen atoms (below 1 at.\%) already

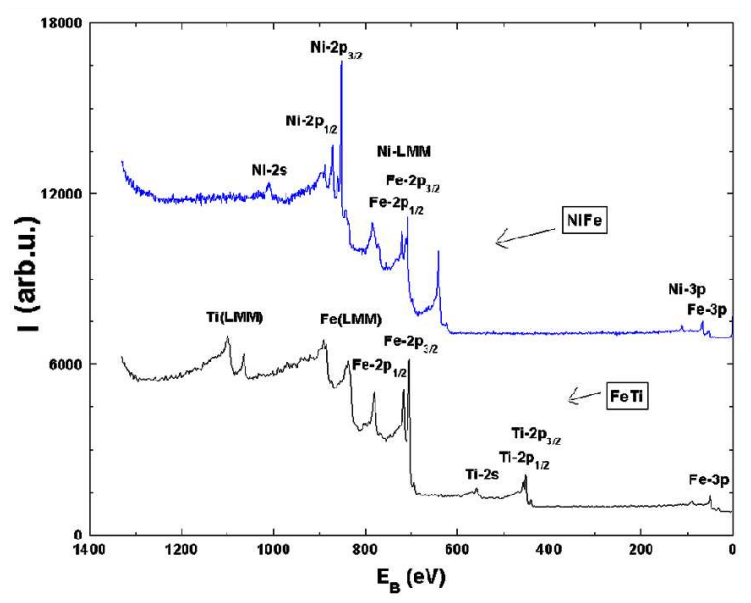

Fig. 1. XPS spectra (Al $K_{\alpha}$ ) of in situ prepared NiFe and FeTi alloy thin films. The total thickness of the samples was about $1000 \mathrm{~nm}$.

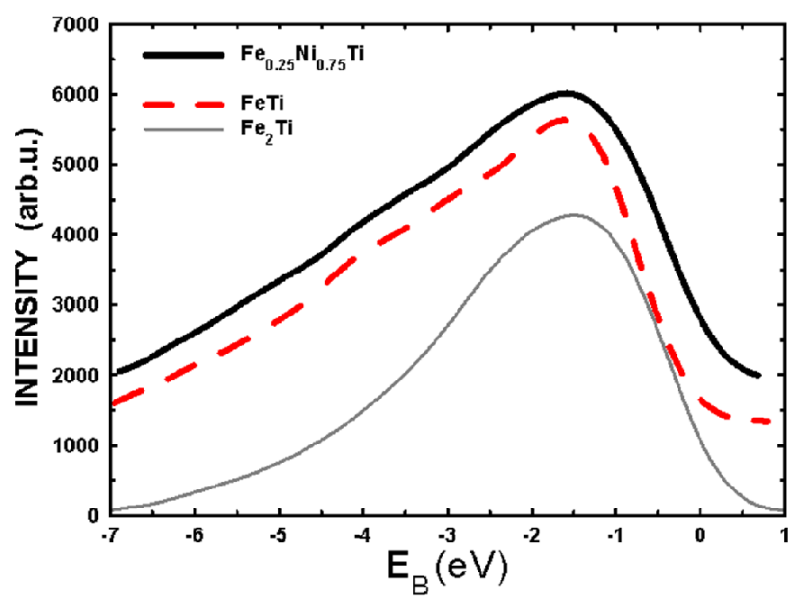

Fig. 2. XPS (Al $\left.K_{\alpha}\right)$ valence band for nanocrystalline $\mathrm{FeTi}, \mathrm{Fe}_{2} \mathrm{Ti}$ and $\mathrm{Fe}_{0.25} \mathrm{Ni}_{0.75} \mathrm{Ti}$ alloy thin films. The total thickness of the samples was about $1000 \mathrm{~nm}$.

adsorbed on Ti based alloy thin film surfaces $3 \mathrm{~h}$ after preparation. Note that the sample was kept in the UHV of $6 \times 10^{-11} \mathrm{mbar}$.

In Fig. 2 we show the XPS valence bands for nanocrystalline $\mathrm{FeTi}, \mathrm{Fe}_{2} \mathrm{Ti}$ and $\mathrm{Fe}_{0.25} \mathrm{Ni}_{0.75} \mathrm{Ti}$ alloy thin films. The position of the valence band measured for the nanocrystalline FeTi (bold broken line) and $\mathrm{Fe}_{0.25} \mathrm{Ni}_{0.75} \mathrm{Ti}$ (bold solid line) thin films is similar to those measured for the bulk polycrystalline samples [19]. On the other hand, the XPS valence bands of the nanocrystalline samples (see Fig. 2) are broader compared to those reported in Ref. [19] for bulk polycrystalline materials with the same average chemical compositions. The above behaviour could be explained as strong deformation of the nanocrystals [18-20]. For such nanocrystalline samples the interior of the nanocrystal is constrained and the distances between atoms located at the grain boundaries expanded [20]. We have observed earlier very similar valence band broadening for 
the $\mathrm{LaNi}_{5}$-type bulk nanocrystalline alloys [18]. The considerable broadening of the valence band observed for the $\mathrm{Fe}_{0.25} \mathrm{Ni}_{0.75} \mathrm{Ti}$ thin film (bold solid line in Fig. 2) is in good agreement with results obtained for the bulk mechanically alloyed sample [19]. However, the microstructure of ball-milled samples is rather complicated. It can contain defects such as grain boundaries, dislocations, and impurity atoms in a high number density [14]. Local stress between the adjacent nanograins is also expected. Also, thin films and multilayers usually have microstructural defects [15]. Therefore, it is possible a significant broadening of the valence band for the nanocrystalline materials.

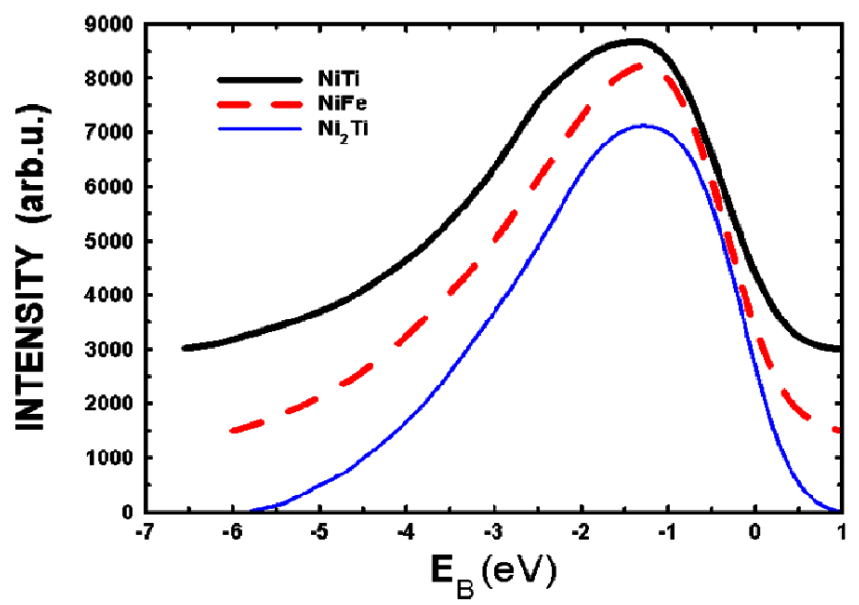

Fig. 3. XPS $\left(\mathrm{Al} K_{\alpha}\right)$ valence band for $\mathrm{NiFe}, \mathrm{NiTi}$ and $\mathrm{NiTi}_{2}$ alloy thin films. The total thickness of the samples was about $1000 \mathrm{~nm}$.

The experimental XPS valence bands measured for nanocrystalline $\mathrm{NiFe}, \mathrm{NiTi}$ and $\mathrm{NiTi}_{2}$ alloy thin films are shown in Fig. 3. We have also observed broadening of the valence band measured for the nanocrystalline thin film samples compared to those determined for the polycrystalline bulk materials reported in Ref. [21]. Furthermore, the position of the XPS valence band maximum measured for the nanocrystalline NiTi thin film (bold solid line in Fig. 3) is shifted towards higher binding energy compared to $a b$ initio DOS calculations [22]. Note that the theoretical calculations were performed for the perfect crystal structure. Therefore, the shift and broadening of the experimental valence band could be explained by the specific nanocrystalline microstructure of the thin film sample. Such a modification of the valence band of the nanocrystalline alloy compared to that measured for the polycrystalline sample could significantly improve the discharge capacity [22].

\section{Conclusions}

The different microstructure observed in polycrystalline and nanocrystalline alloy thin film leads to significant modifications of their electronic structure. Especially, such a modification of the valence bands of the nanocrystalline $\mathrm{Fe}-\mathrm{Ni}-\mathrm{Ti}$ alloy thin films compared to those measured for polycrystalline samples could significantly influence on their hydrogenation properties in agreement with semi-empirical models.

\section{Acknowledgments}

This work was supported by NCBiR, project no. POKL.04.03.00-00-015/12.

\section{References}

[1] Y. Fukoi, The Metal-Hydrogen System, 2nd ed., Springer, Berlin 2005.

[2] A. Pundt, R. Kirchheim, Ann. Rev. Mater. Res. 36, 555 (2006).

[3] M. Latroche, J. Phys. Chem. Solids 65, 517 (2004).

[4] E. Akiba, Curr. Opin. Solid Mater. Sci. 4, 267 (1999).

[5] A. Züttel, L. Schlapbach, Nature 414, 353 (2001).

[6] M. Conte, P.P. Prosini, S. Passerini, Mater. Sci. Eng. B 108, 2 (2004).

[7] L. Schlapbach, Hydrogen in Intermetallic Compounds II, Springer, Berlin 1992, p. 165.

[8] R. Griessen, Phys. Rev. B 38, 3690 (1988).

[9] A. Züttel, P. Wenger, P. Sudan, Ph. Mauron, S. Orimo, Mater. Sci. Eng. B 108, 9 (2004).

[10] S. Orimo, H. Fujii, Appl. Phys. A 72, 167 (2001).

[11] A. Pundt, Adv. Eng. Mater. 6, 11 (2004).

[12] A. Zaluska, L. Zaluski, J.O. Ström-Olsen, J. Alloys Comp. 253-254, 70 (1997).

[13] A. Borgschulte, R.J. Westerwaal, J.H. Rector, B. Dam, R. Griessen, Appl. Phys. Lett. 85, 4884 (2004).

[14] H. Gleiter, Acta Mater. 48, 1 (2000).

[15] M. Ohring, The Materials Science of Thin Films, Academic Press, San Diego 1991.

[16] W.D. Nix, Metall. Trans. A 20, 2217 (1989).

[17] L. Smardz, U. Köbler, W. Zinn, J. Appl. Phys. 71, 5199 (1992).

[18] L. Smardz, M. Nowak, M. Jurczyk, Int. J. Hydrogen En. 37, 3659 (2012).

[19] K. Smardz, L. Smardz, M. Jurczyk, E. Jankowska, Phys. Status Solidi A 196, 263 (2003).

[20] M.R. Fitzsimmons, J.A. Estman, R.A. Robinson, A.C. Lawson, J.D. Thompson, R. Morshovich, Phys. Rev. B 48, 8245 (1993).

[21] S. Shabalovskaya, A. Narmonev, O. Ivanova, A. Dementjev, Phys. Rev. B 48, 13296 (1993).

[22] A. Szajek, M. Makowiecka, E. Jankowska, M. Jurczyk, J. Alloys Comp. 403, 323 (2005). 